\title{
Gambaran Kehamilan dengan Luaran Makrosomia Periode Januari - Desember 2014 di RSUP Prof. Dr. R. D. Kandou Manado
}

\author{
${ }^{1}$ Stelaine Osok \\ ${ }^{2}$ John J.E. Wantania \\ ${ }^{2}$ Maya E. Mewengkang
}

\author{
${ }^{1}$ Kandidat Skrispi Fakultas Kedokteran Univeritas Sam Ratulangi Manado \\ ${ }^{2}$ Bagian Obstetri-Ginekologi Fakultas Kedokteran Universitas Sam Ratulangi Manado \\ Email: stelaine.osok@yahoo.com
}

\begin{abstract}
According to the American College of Obstetricians and Gynecologist and the World Health Organization, an infant who has a birth weight of more than 8 pounds $(4.000$ gram) is diagnosed as macrosomia. There are some risk factors that arise from fetal macrosomia such as diabetes, maternal obesity, and excessive weight gain during pregnancy. These risk are directly related to the birth weight of the infant and begin to increase substantially when birth weight exceeds 4.000 gram especially when it is more than 5.000 gram. This study was aimed to identify the description of pregnancy with macrosomia. This was a descriptive retrospective study. Data were obtained from patient records and survey in the Maternity Department of Prof. Dr. R. D. Kandou Manado. The results showed that the number of total pregnancies with macrosomia were 202 from 3,347 cases. The most common cases were multigravida with macrosomia (128 cases), gestational age 37-40 weeks (80 cases), maternal weight $61-80 \mathrm{~kg}$ (97 cases), and caesarean section as the type of labor (115 cases). Additionaly, most of the macrosomia cases were found in male infants, birth weight 4,000-4,250 grams (88 cases), and suffered from asphyxia.
\end{abstract}

Keywords: the pregnancy, macrosomia

\begin{abstract}
Abstrak: Menurut American College of Obstetricians and Gynecologists and World Health Organization, bayi dengan berat lebih dari 8 ons, 13 ons (4.000 gram) disebut makrosomia. Beberapa faktor risiko yang terkait dengan janin makrosomia seperti diabetes serta ibu dengan obesitas dan kenaikan berat badan yang berlebihan selama kehamilan. Risiko ini secara langsung berhubungan dengan berat badan lahir bayi dan mulai meningkat secara substansial ketika berat badan lahir melebihi 4.500 gram dan terutama ketika melebihi 5.000 gram. Penelitian ini bertujuan untuk mengetahui gambaran kehamilan dengan luaran makrosomia. Jenis penelitian ialah deskriptif retrospektif menggunakan catatan rekam medik pasien dan pendataan di bagian ruang bersalin RSUP Prof. Dr. R. D. Kandou Manado. Hasil penelitian mendapatkan jumlah kehamilan dengan luaran makrosomia sebanyak 202 dari 3.347 kasus yang tercatat dan terbanyak pada usia ibu 35-40 tahun (42 kasus). Luaran makrosomia terbanyak pada multigravida (128 kasus), usia kehamilan 37-40 minggu (80 kasus), berat badan ibu 61-80 kg (97 kasus), dan jenis persalinan seksio sesarea (115 kasus). Luaran makrosomia terbanyak pada bayi laki-laki dengan berat badan 4.000-4.250 gram (88 kasus), dan pada bayi asfiksia. Simpulan: Jumlah makrosomia sebanyak 202 kasus, terbanyak pada usia ibu 35-40 tahun, multigravida, usia kehamilan 37-40 minggu, berat badan ibu $61-80 \mathrm{~kg}$, persalinan seksio sesarea, terbanyak pada bayi laki-laki dengan berat badan 4.000-4.250 gram dan bayi asfiksia.
\end{abstract}

Kata kunci: gambaran kehamilan, luaran makrosomia 
Menurut American College of Obstetricians and Gynecologis and World Health Organization, bayi dengan berat lebih dari 8 ons, 13 ons (4.000 gram) disebut makrosomia. ${ }^{1,2}$ Makrosomia dapat didiagnosis ketika berat lahir melebihi batas yang ditetapkan yaitu 4.000 gram atau 4.500 gram. ${ }^{3,4}$

Kelahiran bayi seberat 16 pon $(7.300$ gram) di Amerika Serikat pada tahun 1979 dipublikasikan secara luas. Neonatus terbesar yang dikutip dalam Guinnes Book of World Record ialah bayi laki-laki seberat 23 pon 12 ons (10.800 gram) yang dilahirkan oleh seorang perempuan kebangsaan Kanada, Anna Bates pada tahun 1979 (Barnes, 1957). Terdapat beberapa faktor yang menyebabkan makrosomia pada janin yaitu obesitas, diabetes - gestasional tipe dua, kehamilan lebih bulan, multiparitas, orang tua bertubuh besar, usia maternal lanjut, riwayat bayi makrosomia sebelumnya, faktor ras, dan etnik. ${ }^{4}$

Beberapa faktor risiko yang terkait dengan janin makrosomia seperti diabetes (makrosomia terdeteksi $70-80 \%$ pada kehamilan dengan komplikasi diabetes melitus tiga), ibu dengan obesitas dan berat badan yang berlebihan selama kehamilan. ${ }^{5}$

Ibu dengan diabetes merupakan salah satu faktor risiko tertinggi yang berhubungan dengan persalinan bayi yang dianggap besar untuk usia kehamilan. Pregestational dan diabetes gestasional mengakibatkan janin makrosomia sebanyak $50 \%$ dari kehamilan dengan komplikasi diabetes gestasional dan $40 \%$ dari komplikasi diabetes mellitus tipe satu. ${ }^{6}$

Pengaruh peningkatan obesitas pada ibu sangat berarti. Seorang ibu di Parkland Hospital melahirkan bayi dengan berat > 5.000 gram memiliki indeks massa tubuh (IMT) rata-rata $37,8 \mathrm{~kg} / \mathrm{cm}^{2}$ dan $20 \%$ diantaranya ialah penyandang diabetes. Berdasarkan sumber dari Cochrane Database, Henriksen (2008) melaporkan bahwa peningkatan pesat prevalensi bayi berukuran besar diakibatkan oleh obesitas dan diabetes tipe dua pada ibu. ${ }^{3}$

Komplikasi pada ibu termasuk perdarahan postpartum, korioamnionitis, pelahiran sesar dan memperpanjang waktu perawatan. Komplikasi pada janin ialah pelahiran distosia bahu, cedera pleksus brakialis, cedera tulang, aspirasi mekonium, perinatal aspiksia, hipoglikemi, hipokalsemia, cedera klavikula, kesulitan bernapas dan nilai apgar yang rendah. ${ }^{7}$

Neonatus makrosomia berisiko untuk pelahiran distosia bahu dan trauma kelahiran. Risiko ini secara langsung berhubungan dengan berat badan lahir bayi dan mulai meningkat secara substansial ketika berat badan lahir melebihi 4500 gram dan terutama ketika melebihi 5000 gram. ${ }^{6}$ Distosia tersebut terjadi ketika panggul ibu berukuran proporsional untuk memungkinkan pelahiran kepala janin, namun kurang besar untuk memungkinkan pelahiran bahu janin yang berdiameter lebih besar. ${ }^{4}$

\section{METODE PENELITIAN}

Jenis penelitian ialah deskriptif retrospektif menggunakan catatan rekam medik pasien dan pendataan di ruang bersalin bagian Kebidanan dan Kandungan RSUP Prof. Dr. R. D. Kandou Manado.

\section{HASIL PENELITIAN}

Hasil penelitian yang dilakukan di RSUP Prof. dr. R. D. Kandou berdasarkan pengambilan data di Ruang Bersalin dan Instalasi Rekam Medik periode Januari Desember 2014 didapatkan 202 (4,39\%) kasus kehamilan dengan luaran makrosomia dari 3.347 persalinan yang tercatat.

Tabel 1. Distribusi kehamilan dengan luaran makrosomia

\begin{tabular}{lccc}
\hline Tahun & Makrosomia & (n) & $\mathbf{( \% )}$ \\
\hline 2014 & 202 & 3.347 & 4.39 \\
\hline
\end{tabular}

Distribusi kasus makrosomia di RSUP Prof. Dr. R. D.Kandou periode Januari Desember 2014 mendapatkan kasus terbanyak pada golongan usia 35-40 tahun berjumlah 42 kasus $(28,57 \%)$, diikuti golongan usia 30-34 tahun sebanyak 38 kasus $(25,85 \%)$. Golongan usia yang paling 
sedikit yaitu $>40$ tahun sebanyak 4 kasus $(2,72 \%)$.

Tabel 2. Distribusi makrosomia berdasarkan usia ibu

\begin{tabular}{ccc}
\hline Usia ibu & $(\mathbf{n})$ & $(\boldsymbol{\%})$ \\
\hline$<20$ & 5 & 3.40 \\
$20-24$ & 24 & 16.33 \\
$25-29$ & 34 & 23.13 \\
$30-34$ & 38 & 25.85 \\
$35-40$ & 42 & 28.57 \\
$>40$ & 4 & 2.72 \\
Total & 147 & 100 \\
\hline
\end{tabular}

Distribusi kasus makrosomia berdasarkan jumlah paritas melalui pengambilan data di bagian ruang bersalin RSUP Prof. dr. R.D Kandou periode Januari Desember 2014, didapatkan tersering pada ibu dengan jumlah paritas multigravida sebanyak 128 kasus (87.1\%) dan yang paling rendah pada ibu dengan jumlah paritas primigravida dengan 19 kasus $(12,9 \%)$.

Tabel 3. Distribusi Makrosomia berdasarkan jumlah paritas

\begin{tabular}{ccc}
\hline Jumlah paritas & $(\mathbf{n})$ & $\mathbf{( \% )}$ \\
\hline Primigravida & 19 & 12,9 \\
Multigravida & 128 & 87,1 \\
Total & 147 & 100 \\
\hline
\end{tabular}

Distribusi makrosomia berdasarkan usia kehamilan melalui pengambilan data di ruang bersalin RSUP Prof. Dr. R. D. Kandou periode Januari - Desember 2014, didapatkan jumlah kasus terbanyak pada usia kehamilan 37-40 minggu yaitu 80 kasus $(54,42 \%)$ dan yang paling sedikit pada usia kehamilan >41 minggu yaitu 18 kasus $(12,25 \%)$.

Distribusi kasus makrosomia berdasarkan berat badan ibu melalui pengambilan data di bagian ruang bersalin RSUP Prof. Dr. R.D.Kandou periode Januari Desember 2014, didapatkan kasus terbanyak pada ibu dengan berat badan 61 - $80 \mathrm{~kg}$ yaitu 97 kasus $(65,9 \%)$ dan diikuti pada ibu dengan berat badan yaitu $81-100$ kg yaitu 35 kasus (23,8\%). Kasus makrosomia terendah terdapat pada ibu dengan berat badan $>100 \mathrm{~kg}$ yaitu 4 kasus $(2,8 \%)$.

Tabel 4. Distribusi Makrosomia berdasarkan usia kehamilan

\begin{tabular}{ccc}
\hline Usia Kehamilan & $(\mathbf{n})$ & $\mathbf{( \% )}$ \\
\hline $37-40$ minggu & 80 & 54,42 \\
$40-41$ minggu & 49 & 33,33 \\
$>41$ minggu & 18 & 12,25 \\
Total & 147 & 100 \\
\hline
\end{tabular}

Tabel 5. Distribusi makrosomia berdasarkan berat badan ibu

\begin{tabular}{ccc}
\hline Berat badan $\mathbf{( k g )}$ & $\mathbf{( n )}$ & $\mathbf{( \% )}$ \\
\hline$<60$ & 11 & 7,5 \\
$61-80$ & 97 & 65,9 \\
$81-100$ & 35 & 23,8 \\
$>100$ & 4 & 2,8 \\
Total & 147 & 100 \\
\hline
\end{tabular}

Distribusi makrosomia berdasarkan jenis persalinan melalui pengambilan data di RSUP Prof. Dr. R. D.Kandou periode Januari-Desember 2014, didapatkan jumlah kasus terbanyak pada persalinan seksio sesarea yaitu 115 kasus $(78,23 \%)$ dan yang paling sedikit pada persalianan pervaginam yaitu 32 kasus $(21,77 \%)$.

Tabel 6. Distribusi Makrosomia berdasarkan jenis Persalinan

\begin{tabular}{ccc}
\hline Jenis Persalinan & $(\mathrm{n})$ & $(\%)$ \\
\hline Seksio Sesarea & 115 & 78.23 \\
Pervaginam & 32 & 21.77 \\
Total & 147 & 100 \\
\hline
\end{tabular}

Distribusi kasus makrosomia berdasarkan jenis kelamin di RSUP Prof. Dr. R. D Kandou periode Januari-Desember 2014, mendapatkan jumlah kasus pada bayi laki laki (85 kasus; 57,8\%) lebih banyak daripada bayi perempuan (62 kasus; $42,2 \%)$.

Tabel 7. Distribusi makrosomia berdasarkan jenis kelamin bayi

\begin{tabular}{ccc}
\hline Jenis kelamin & $(\mathrm{n})$ & $(\%)$ \\
\hline Laki-laki & 85 & 57,8 \\
Perempuan & 62 & 42,2 \\
Total & 147 & 100 \\
\hline
\end{tabular}


Distribusi kasus makrosomia berdasarkan berat badan bayi di RSUP Prof. dr. R. D. Kandou periode Januari Desember 2014, didapatkan kasus terbanyak pada berat badan bayi 4.000 4.250 gram yaitu 88 kasus $(59.86 \%)$. Kasus paling rendah terdapat pada berat badan $>5.000$ gram yaitu 2 kasus $(1.4 \%)$.

Tabel 8. Distribusi makrosomia berdasarkan berat badan bayi

\begin{tabular}{ccc}
\hline BB Bayi (gram) & (n) & $(\boldsymbol{\%})$ \\
\hline $4.000-4.250$ & 88 & 59.86 \\
$4.251-4.500$ & 38 & 25.85 \\
$4.501-4.750$ & 13 & 8.84 \\
$4.751-5.000$ & 6 & 4.1 \\
$>5.000$ & 2 & 1.4 \\
Total & 147 & 100 \\
\hline
\end{tabular}

Distribusi makrosomia berdasarkan nilai apgar di RSUP Prof. Dr. R. D. Kandou periode Januari-Desember 2014, didapatkan jumlah kasus bayi bugar sebanyak 48 kasus $(32,6 \%)$, asfiksia sebanyak 95 kasus $(64,6 \%)$ dan yang terendah adalah bayi mati sebanyak 4 kasus $(2,8 \%)$.

Tabel 9. Distribusi makrosomia berdasarkan Apgar score

\begin{tabular}{ccc}
\hline Apgar score & $(\mathbf{n})$ & $\mathbf{( \% )}$ \\
\hline Bayi bugar & 48 & 32.6 \\
Asfiksia & 95 & 64.6 \\
Bayi mati & 4 & 2.8 \\
Total & 147 & 100 \\
\hline
\end{tabular}

\section{BAHASAN}

Pada penelitian retrospektif berdasarkan pengambilan data di RSUP Prof. Dr. R. D. Kandou Manado periode Januari-Desember 2014 diperoleh 202 kasus kehamilan dengan luaran makrosomia $(4,39 \%)$ dari 3.347 yang tercatat (Tabel 1). Jika dibandingkan dengan penelitian sebelumnya oleh Kusumawati ${ }^{8}$ tentang prevalensi persalinan makrosomia periode 2012 didapatkan sebanyak 204 kasus (4,68\%), maka terlihat adanya penurunan kasus makrosomia pada tahun 2012 dan 2014 di RSUP Prof. Dr. R. D. Kandou Manado.
Kejadian bayi makrosomia (Tabel 2) terbanyak pada usia ibu 35-40 tahun $(28,57 \%)$ dengan jumlah 42 pasien dan diikuti pada usia ibu 30-34 tahun (25,85\%) dengan jumlah 38 pasien, kemudian golongan usia $>40$ tahun $(2,72 \%)$ dari 4 kasus. Penelitian sebelumnya pada periode 2012 juga memiliki hasil yang sama yaitu kasus makrosomia terbanyak pada usia ibu 30-34 tahun. Hal ini dikarenakan makin tua usia ibu hamil maka bertambah berat bayi yang dilahirkan. ${ }^{8}$

Luaran makrosomia yang ditunjukkan pada (Tabel 3) memperlihatkan kasus makrosomia terbanyak pada multigravida yaitu 128 kasus $(87,1 \%)$ dan jumlah paritas primigravida yaitu 19 kasus (12,9\%). Paritas adalah seorang wanita yang sudah pernah melahirkan bayi yang dapat hidup. Uterus yang melahirkan lebih dari satu bayi mengalami perubahan dalam keelastisannya. Semakin banyak melahirkan anak maka uterus akan semakin elastis dan bertambah besar ukurannya. ${ }^{9}$ Oleh sebab itu bisa disimpulkan bahwa ibu dengan jumlah paritas multigravida memungkinkan lebih dominan melahirkan bayi dengan berat badan $>4.000$ gram (makrosomia).

Pada Tabel 4 dapat dilihat bahwa kelahiran makrosomia terbanyak pada usia kehamilan 37-40 minggu (54.42\%) dengan 80 kasus dan yang paling rendah adalah usia kehamilan >41 minggu (12.25\%) dengan 18 kasus.

Kelahiran luaran makrosomia (Tabel 5) memperlihatkan kasus makrosomia terbanyak pada ibu dengan berat badan 61$80 \mathrm{~kg}$ dengan 97 kasus (65.9\%). Banyak faktor yang dapat mengakibatkan makrosomia diantaranya adalah obesitas. Berat badan ibu berpengaruh langsung pada janin, ketika berat badan ibu saat hamil bertambah maka akan mempengaruhi berat badan janin. Hal ini juga diperlihatkan berdasarkan sumber dari Cochrane Database, Henriksen (2008) menyatakan bahwa peningkatan pesat prevalensi bayi berukuran besar diakibatkan oleh obesitas. ${ }^{3}$ Pertambahan berat badan selama kehamilan merupakan cara yang baik untuk menilai kesejahteraan ibu hamil dan ini sangat 
berpengaruh pada bayinya, tetapi jika penambahan berat badan selama kehamilan melebihi yang direkomendasikan maka meningkatkan risiko makrosomia $(\geq 4.000$ gram). ${ }^{10}$

Tindakan persalinan (Tabel 6) yang dilakukan untuk menangani pasien dengan janin yang diperkirakan berat badan melebihi 4.000 gram terbanyak ialah seksio sesarea $78.23 \%$ dari 115 kasus kemudian pervaginam $(21.77 \%)$ dengan 32 kasus. Penelitian pada periode 2012 oleh Kusumawati $^{8}$ melaporkan persalinan seksio sesarea lebih dominan dari persalinan pervaginam. Persalinan pervaginam dapat dicoba untuk taksiran janin hingga 5.000 gram pada ibu tanpa diabetes. Seksio sesarea dipertimbangkan untuk taksiran berat janin $>5.000$ gram pada ibu tanpa diabetes dan $>4.500$ gram pada ibu dengan diabetes.

Kelahiran bayi makrosomia memiliki kasus terbanyak pada jenis kelamin lakilaki sebanyak 85 kasus $(57,8 \%)$, dapat dilihat pada hasil penelitian (Tabel 7). Penelitian periode 2012 yang dilakukan oleh Kusumawati ${ }^{8}$ memiliki hasil yang sama yaitu makrosomia terbanyak pada bayi laki-laki. Hasil penelitian (Tabel 8) menunjukkan kelahiran bayi makrosomia didominasi dengan berat badan 4.000-4.250 gram $(59,86 \%)$ dengan 88 kasus. Kehamilan dengan luaran makrosomia seperti yang diperlihatkan dalam hasil (Tabel 9) terbanyak pada asfiksia yaitu 95 kasus $(64,6 \%)$ dan bayi mati terdapat 4 kasus $(2,8 \%)$. Salah satu komplikasi bagi janin makrosomia adalah nilai apgar score yang rendah. ${ }^{7}$

\section{SIMPULAN}

Dari hasil penelitian yang dilakukan berdasarkan pengambilan data di bagian ruang persalinan RSUP Prof. Dr. R.D Kandou Manado periode Januari-Desember 2014, dapat disimpulkan bahwa kasus kehamilan dengan luaran makrosomia sebanyak 202 kasus (4,39\%), terbanyak pada usia ibu 35-40 tahun, multigravida, usia Kehamilan 37-40 minggu, berat badan ibu 61-80 kg, jenis persalinan seksio sesarea, bayi laki-laki, berat badan bayi 4.000-4.250 gram, dan nilai apgar score pada asfiksia.

\section{SARAN}

Perlu dilakukan penelitian lebih lanjut tentang kehamilan dengan luaran makrosomia berdasarkan pencatatan kasus dengan data yang lebih lengkap lagi.

\section{DAFTAR PUSTAKA}

1. Zamorski MA, Biggs WS. Management of suspected fetal macrosomia. University of Michigan Medical School, Ann Arbor, Michigan. 2001 Jan 15. [cited 2016 Jan 07]. Available from: http://www.aafp.org/ afp/2001 /0115/p302.html)

2. Mayrani. Tanda-tanda dan gejala makrosomia janin. 2013. [cited 2015 Oct 28]

3. Prawirohardjo S. Buku Acuan Nasional Pelayanan Kesehatan Maternal dan Neonatal (1st ed). Jakarta: Yayasan Bina Pustaka Sarwono Prawirohardjo, 2006.

4. Cunningham FG, Leveno KJ, Bloom SL, Rouse DJ, Spong CY. Obstetri Williams (2nd ed). Jakarta: EGC, 2014; p. 900

5. Ali SH, Ishtiaque $\mathbf{S}$. Fetal macrosomia; its maternal and neonatal complications. Professional Med J. 2014;21(3):4216.

6. Najafian M, Cheraghi M; Occurrence of fetal macrosomia rate and its maternal and neonatal complications: s 5-year cohort study. 2012.

7. Wondie T, Jara D, Ayana M; Factors sssociated with macrosomia among neonates delivered at Debre Markos Referal Hospital (Case Control), Northwest Ethiopia, 2014.

8. Kusumawati L. Persalinan dengan luaran makrosomia di BLU RSUP. Prof. Dr. R. D. Kandou (deskriptif retrospektif). Manado: Bagian Obstetri Ginekologi Universitas Sam Ratulangi Manado; 2014

9. Supa S, Sidabutar S: Hubungan antara paritas, berat badan lahir, dan retensio plasenta dengan kejadian perdarahan post partum primer (cross sectional): Surabaya: Akademi Kebidanan Griya 
Osok, Wantania, Mewengkang: Gambaran kehamilan dengan...

Husada Surabaya; 2014

10. Anggarini FD. Hubungan antara berat badan ibu hamil dengan makrosomia (case control). Surakarta: Fakultas Kedokteran Universitas
Muhammadiyah Surakarta; 2013. Available from: http://eprints.ums. ac.id/22648/12/NASKAH_PUBLIKAS I.pdf 